\title{
$18 \mathrm{p}$ - syndrome and hypopituitarism
}

\author{
Henry G Artman, Colleen A Morris, A Dean Stock
}

\begin{abstract}
A patient is described with 18p- syndrome and hypopituitarism. This is the first patient with this syndrome who has been shown to benefit from growth hormone therapy. Patients with this syndrome who have growth deficiency should be considered for evaluation for hypopituitarism, if the quality of their lives would improve with an increase in stature.
\end{abstract}

( $($ Med Genet 1992;29:671-2)

Short stature has been associated with deletion of the short arm of chromosome 18. There have been two reported cases of growth hormone deficiency associated with $18 \mathrm{p}$ - syndrome. ${ }^{12}$ The first patient showed no response to growth hormone and the treatment was not undertaken for the second patient. Another abnormality of chromosome 18 (ring chromosome 18) and growth hormone deficiency has been described and treated successfully. ${ }^{3}$

The aetiology of the growth hormone deficiency in 18p- syndrome is unknown although holoprosencephaly, described in $10 \%$ of cases with $18 \mathrm{p}$-, is associated with growth hormone deficiency. ${ }^{4}$ We describe a patient with $18 \mathrm{p}$ - as the result of an 18;21 translocation who had pituitary hypoplasia, growth hormone deficiency, and a response to growth hormone therapy.

\section{Case report}

A 3 year 9 month old male was referred to the Department of Pediatrics, University of Nevada School of Medicine, for evaluation of poor growth. He was the product of a 33 year old gravida 2, para 2, 36 week pregnancy complicated by toxaemia. The father was aged 35 at the time of the proband's birth. The birth weight was $3175 \mathrm{~g}$ (50th centile) and birth length was $49 \mathrm{~cm}$ (25th centile). Head circumference at birth was $33.5 \mathrm{~cm}$ (approximately 20 th centile). Problems in the newborn period included difficulty in sucking and absence of the rooting reflex. The patient has had persistent failure to thrive consisting of poor linear growth and weight gain beginning at 6 months of age. In addition he had developmental delay. He sat at 8 months and walked at 16 months. The first words were spoken at 17 months and sentences were first used at 31 months. Medical problems included chronic otitis media, pneumonia at the age of 2 , and eczema of the lower extremities treated with topical steroids.

Chromosome studies obtained at $2 \frac{1}{2}$ years showed an 18;21 translocation resulting in an $18 \mathrm{p}$ deletion. Parental chromosome studies were normal. High resolution chromosome studies were performed at the age of 8 years in order to clarify the breakpoints (fig 1). The karyotype is $45, \mathrm{XY},-18,-21,+\operatorname{der}(18)$ $\mathrm{t}(18 ; 21)(\mathrm{p} 11.23$; 111.2$)$. This de novo translocation resulted in a partial deletion of the short arm of chromosome 18, including 18 pl1.23 $\rightarrow 18$ pter. Thyroid function tests showed normal values for total $\mathrm{T} 4 \mathrm{of} 6.7 \mu \mathrm{g} / \mathrm{dl}$ and T3 of $156 \mathrm{ng} / \mathrm{dl}$. Bone age at $2 \frac{1}{2}$ years was interpreted as being one year delayed.

At the time of presentation ( 3 years 9 months), he was $86.5 \mathrm{~cm}$ in height, $4 \mathrm{SD}$ below the mean. Head circumference was on the 50th centile. Weight was $11.4 \mathrm{~kg}, 2 \mathrm{SD}$ below the mean. At re-evaluation aged 5 years 6 months, mild dysmorphic facial features were noted (fig 2). His interpupillary distance of $43 \mathrm{~mm}$

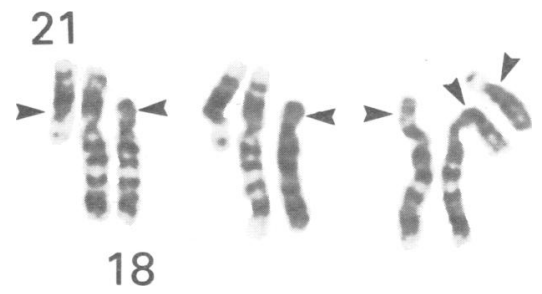

Figure 1 Comparison of $G$ banded chromosomes at approximately the 600 band level (left) to the 800 band level (right) of resolution. In each triplet, chromosome 21 is on the left, followed by the derived $t(18 ; 21)$, and chromosome 18. The arrows indicate the breakpoints involved in forming the derived chromosome, which is interpreted as $45, X Y,-18,-21,+\operatorname{der}(18) t(18 ; 21)$ (p11.23;q11.2).

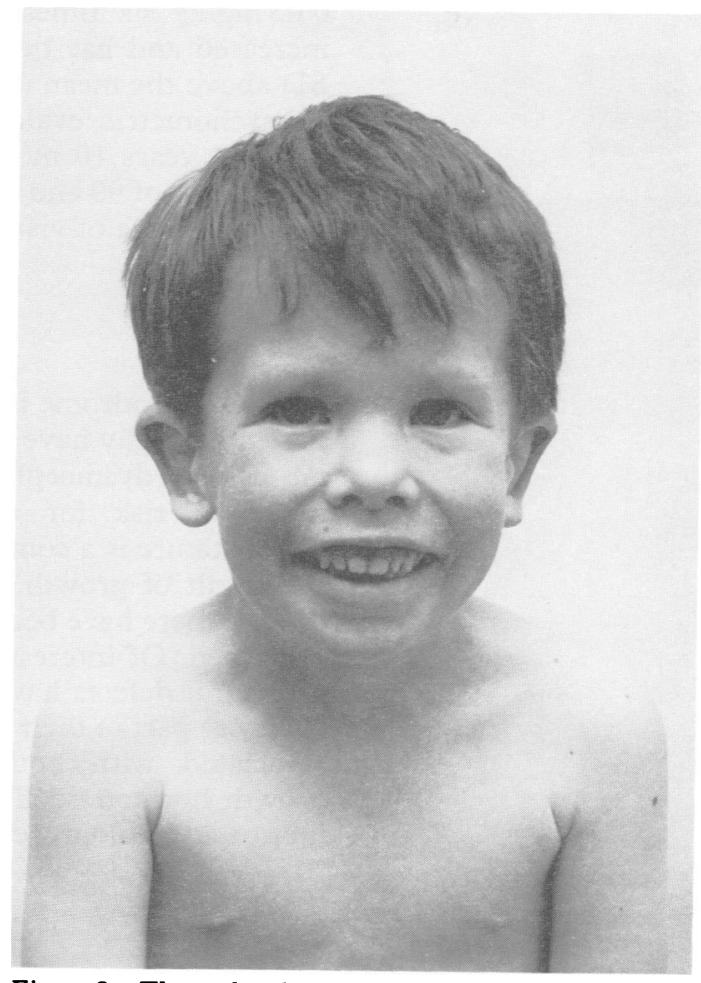

Figure 2 The proband aged 6 years. 
was below the 3 rd centile. He had periorbital fullness, a tent shaped upper lip, short philtrum, wide mouth, and micrognathia. The ears measured on the 90th centile and had mild lateral protrusion. The hands were less than the 3 rd centile. There was bilateral fifth finger clinodactyly and hallux valgus. His feet also measured less than the 3rd centile. Elbows were hyperextensible and generalised hypotonia was present. The third toe was set back on the right foot.

Bone age was delayed by two years. Serial growth measurements continued to show slow growth over the next seven months despite discontinuation of topical steroids. His endocrine status showed thyroid function tests to be normal with an adjusted $\mathrm{T} 4 \mathrm{of} 10 \mu \mathrm{g} / \mathrm{dl}$ and a TSH of $1.4 \mathrm{IU} / \mathrm{ml}$. Clonidine $\left(150 \mu \mathrm{g} / \mathrm{m}^{2}\right)$ and L-Dopa $(250 \mathrm{mg}$ ) were used to stimulate growth hormone release. Only one sample had a significant increase in serum growth hormone: $8.4 \mathrm{ng} / \mathrm{ml}$ (normal response is greater than $10 \mathrm{ng} / \mathrm{ml}$ ). The remainder of the samples obtained were less than $4 \mathrm{ng} / \mathrm{ml}$. Insulin hypoglycaemia was induced. Serum cortisol increased in a normal fashion to $32.6 \mu \mathrm{g} / \mathrm{dl}$ at 45 minutes after $0 \cdot 1 \mathrm{U} / \mathrm{kg}$ of regular insulin was intravenously administered. An MRI scan of the brain showed hypoplasia of the hypothalmus and pituitary gland. Dental enamel hypoplasia was diagnosed at 4 years and was treated by capping.

During the seven month observation period when no topical steroids were used, the proband grew at a rate of $3.4 \mathrm{~cm}$ per year, which is more than 2 SD below the mean growth rate for his age. The patient was initially treated with $0.1 \mathrm{mg} / \mathrm{kg}$ of synthetic growth hormone (Protropin) subcutaneously three times per week. Because there was a slowing in catch up growth after 16 months of growth hormone therapy, the dosage regimen was changed to $0.05 \mathrm{mg} / \mathrm{kg}$ six times per week. Growth rate increased and has been at $8.5 \mathrm{~cm}$ per year, 2 SD above the mean (fig 3).

Psychometric evaluation performed at the age of 4 years 10 months showed a Stanford Binet score of 99 and specific learning disabilities in the area of visual motor integration.

\section{Discussion}

The 18p- syndrome is a well described entity. Patients usually have mental retardation, dental caries, dysmorphic facial features, and increased risk for autoimmune disorders. Short stature is a common feature and may be the result of growth hormone deficiency, although there have been only two such patients described. Of interest is the fact that midline structural defects have growth hormone deficiency as part of their continuum. Two defects associated with both $18 \mathrm{p}$ - syndrome and growth hormone deficiency are single central incisor and holoprosencephaly. ${ }^{4}$

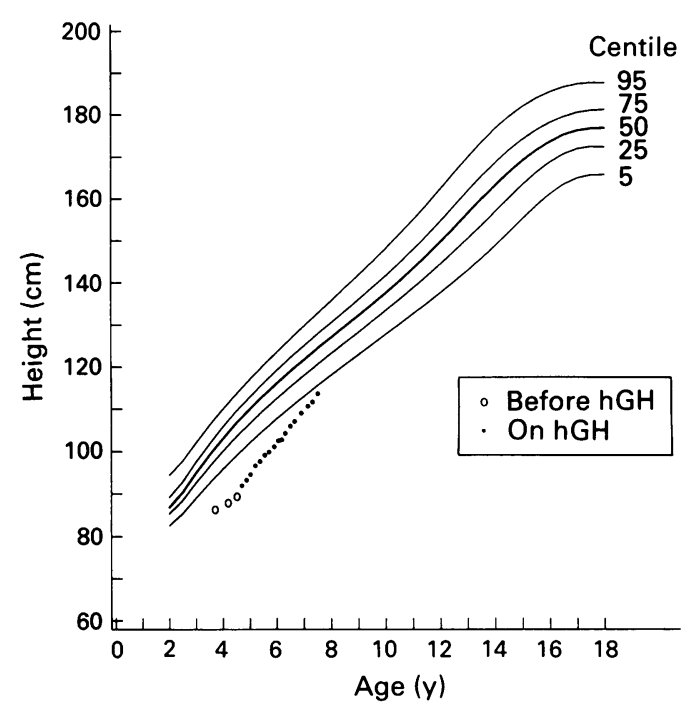

Figure 3 The proband's growth chart illustrating growth during glucocorticoid free period before the use of hGH (human growth hormone) and while proband was receiving $h G H$.

One child reported by Leisti et al ${ }^{1}$ did not respond to growth hormone therapy. This may be because of the age of the patient ( 12 years), the lower dose and less frequent administration (two per week), a less potent preparation of growth hormone (a pituitary extract), or the multifactorial cause of short stature in this syndrome. ${ }^{1}$ Our patient has a clear cut acceleration in linear growth and is now just under $2 \mathrm{SD}$ below the mean in height. As in our patient, normal or borderline intelligence has been reported in two previous cases. ${ }^{67}$ The relatively mild manifestations of the $18 \mathrm{p}$ - syndrome in our patient may in part be the result of the small deletion of chromosome 18 . In the patient described with ring 18 chromosome the location and extent of deletion was not determined. Although the patient was responsive to growth hormone therapy, hypopituitarism secondary to neonatal hypoxia could not be excluded aetiologically.

In summary, we report here the third patient with $18 \mathrm{p}$ - and hypopituitarism. Patients with the $18 \mathrm{p}$ - syndrome should have an evaluation for growth hormone deficiency as the potential for replacement therapy may help to improve their quality of life.

1 Leisti J, Leisti S, Perheentupa J, Sarilahti E, Aula P Absence of IgA and growth hormone deficiency associated with short arm deletion of chromosome 18. Arch Dis Child with short arm

2 Buffoni L, Tarateta A, Aicardi G, Vianello MG, Bonioli E. Nanismo ipofisario e sindrome malformativa multipla "tipo Goldenhar" in soggetto con delezione del braccio corto del cromosoma 18. Min Pediatr 1976;28:716-29.

3 Abusrewil SS. Growth hormone, suspected gonadotrophin deficiency and ring 18 chromosome. Arch Dis Child 1988;63:1090-1.

4 Schinzel A. Catalogue of unbalanced chromosome aberrations in man. New York: Walter de Gruyer, 1983:604.

5 Gluckman PD. Autoimmune thyroiditis in a case of $18 \mathrm{p}-$ syndrome. Aust Paediatr f 1977;13:122-4.

6 Schmidt A, Passarge E. Variable mental development associated with deletion of the short arm of chromosome 18. Clin Genet 1981;20:390-1.

7 Cooksley WGE. Monosomy of a "G" autosome in a 22-yearold female. Med J Aust 1973;2:178-80. 